\title{
EL CONTEXTO DE LA PANDEMIA, UNA OPORTUNIDAD PEDAGÓGICA PARA FORTALECER LA BIODIVERSIDAD Y LA CULTURA
}

\author{
THE CONTEXT OF THE PANDEMIC, A PEDAGOGICAL \\ OPPORTUNITY TO STRENGTHEN BIODIVERSITY AND \\ CULTURE
}

Delia Rincón Ariza*

\begin{abstract}
"Quizás la pandemia actual sea una oportunidad para tomar nota del enorme costo colectivo de los cambios radicales en los estilos de vida ... y fomentar una mejor gestión de estos cambios, particularmente en nuestra relación con la naturaleza"
\end{abstract}

Audrey Azoulay, Directora General de la UNESCO

* Magíster en Gestión Ambiental de los Llanos. Estudiante del Doctorado en Educación y Cultura Ambiental de la Universidad Surcolombiana. Docente de la Universidad de los Llanos, Colombia.

drincon@unillanos.edu.co 0000-0002-0356-2880

Cómo citar este artículo: Rincón, A. D. (2021). El contexto de la pandemia, una oportunidad pedagógica para fortalecer la biodiversidad y la cultura. Revista PACA 11, pp. 197-213.
Resumen: Este documento considera la biodiversidad y la cultura como una oportunidad pedagógica para fortalecerse en tiempos de pandemia. Por ello se propone una estrategia pedagógica alternativa comunitaria que permita avanzar en la construcción de una cultura ambiental, teniendo como ejes para su desarrollo: la biodiversidad como ambiente de aprendizaje, la biodiversidad como ambiente de investigación, la biodiversidad como sistema alternativo ecosocial. Así mismo, aborda la cultura y la biodiversidad como industria a cargo de las diversas organizaciones o instituciones, y la mirada cultural desde las etnias.

Palabras clave: cultura, biodiversidad, pandemia, estrategia alternativa comunitaria.

Abstract: This essay considers biodiversity and culture as a pedagogical opportunity to strengthen itself in times of pandemic. For this reason, an alternative community pedagogical strategy is proposed that allows progress in 
the construction of an environmental culture, having as axes for its development: biodiversity as a learning environment, biodiversity as a research environment, biodiversity as an alternative eco-social system. Likewise, it addresses culture and biodiversity as an industry in charge of various organizations or institutions, and the cultural perspective from ethnic groups.

Keywords: culture, biodiversity, alternative community strategy.

\section{Introducción}

El año 2020 marcó una nueva era para la sociedad del siglo XXI, la cotidianidad del ser humano, de la industria, la naturaleza se vio intervenida por la pandemia del Covid-19. Las autoridades chinas, el 31 de diciembre de 2019 reportaron a la Organización Mundial de la Salud (OMS) la aparición en la provincia Wahan de una extraña enfermedad considerada inicialmente como zoonótica, la cual fue denominada como COVID-19, que afecta principalmente al sistema respiratorio. En el mes de enero de 2020 se reportaron casos en China, Japón, Corea, Tailandia, Alemania e Italia. En febrero, en Estados Unidos, España y Reino Unido.

Teniendo en cuenta dichos sucesos, y los más de 118.000 casos reportados, la Organización Mundial de la Salud, el 11 de marzo de 2020 declaró la pandemia por la enfermedad del nuevo coronavirus, COVID-19 (Idrovo, Manrique \& Nieves, 2020). En América Latina se tuvo el primer reporte el 26 de febrero en Brasil; en el mes de junio la región se catalogó como epicentro de la enfermedad, dado que las medidas para contrarestar la propagación no se abordaron de manea inmediata (Azerrat, Ratto, \& Fantozzi, 2021).

De acuerdo con la Organización de las Naciones Unidas para la Educación, la Ciencia y la Cultura (UNESCO), los individuos se han adaptado en el territorio a su biodiversidad biológica y cultural. No obstante, ante la inadecuada interacción entre el sistema natural y el sistema sociocultural, el mundo se enfrentó a una crisis en salud con el surgimiento del Covid - 19, pandemina que visibilizó los vínculos fuertes entre la naturaleza y los humanos.

El Fondo Mundial para la Naturaleza - WWF INTERNACIONAL (2020), llama la atención sobre el papel fundamental de conservar y mantener la naturaleza para sostener la salud humana y, por tanto la vida en el planeta. 
Podría considerarse que es la vida del hombre la que está pendiendo de un hilo, y aún no toma conciencia ni acciones contundentes para minimizar el impacto de la pandemia en él mismo.

En Colombia, el Ministerio de Protección Social confirmó el 6 de marzo de 2020, el primer caso en una mujer de 19 años que procedía de Milán, Italia. Teniendo en cuenta dicho suceso, el país adoptó en esencia tres medidas: 1 ) medidas sanitarias y de emergencia sanitaria; 2) de emergencia social y económica, y 3 ) de orden público y de carácter ordinario (García Echeverry, Moreno Amézquita, Pinto Bustamante, \& Gómez Cordoba, 2020).

Esta enfermedad zoonótica y emergente, que cada vez se va tornando un poco más agresiva y contagiosa, insta a la comunidad científica en las diferentes regiones del mundo para que se apoyen en procesos de investigación de punta, y de esta manera seguir trabajando por la consolidación de vacunas que permitan combatir el Covid-19 y sus diversas mutaciones, que día a día viene cobrando la vida de un número importante de seres humanos.

El panorama interpuesto por la pandemia increpa a los ciudadanos para que reflexionen, comprendan, valoren y evalúen las prácticas cotidianas en la relación con el sistema natural. Esta nueva situación hace necesaria la construcción de alternativas de solución, desde los diferentes campos del saber, apoyados en la investigación como uno de los ejes fundamentales para estructurar una ruta basada en el conocimiento y la innovación, que permita atender la crisis sanitaria, económica, social, ambiental, cultural y política por la que el mundo está atravesando.

Es un llamado a la reivindicación del hombre con su entorno y la biodiversidad, con la revisión, ajuste, y cambio en el modelo económico impuesto y acelerado, a costa de la sobreexplotación de los recursos naturales, así como la revisión de algunas de las prácticas mal concebidas y realizadas hasta el momento.

En aras de aportar a la comprensión y aplicación de prácticas culturales alrededor de la naturaleza, se requiere desarrollar proyectos pedagógicos e investigativos que propicien sinergias entre la biodiversidad, la educación y la cultura, con el fin de adoptar estrategias formativas que permitan 
promover cambios en el comportamiento humano, encaminados a reconstruir una cultura ambiental individual y colectiva alrededor de la conservación de la biodiversidad y del sistema natural.

En este sentido vale la pena preguntarse, ¿de qué manera el contexto de la pandemia se puede considerar una oportunidad pedagógica para fortalecer la biodiversidad y la cultura? Con el fin de responder a la pregunta, este escrito indaga en dos ejes temáticos de gran importancia: la biodiversidad y la cultura, temas amplios y complejos que pueden abordarse desde varias miradas. Sin embargo, este texto lo considera desde el manejo de la cultura y la biodiversidad como industria a cargo de las diversas organizaciones o instituciones, y desde la mirada cultural étnica.

Por ello, se plantea esta oportunidad a partir de la formulación de una estrategia pedagógica alternativa comunitaria que busca promover una cultura ambiental que incentive el inicio de cambios en el comportamiento humano, a partir de sus interacciones con otros sujetos sociales, que puedan promover espacios para la valoración, la comprensión y la aplicación del conocimiento in situ, y el producido en las investigaciones adelantadas en diferentes contextos.

\section{LA BIODIVERSIDAD Y LA CULTURA}

Abordar la biodiversidad y la cultura, configuran las distintas maneras que el hombre ha intervenido el mundo natural, ya sea desde las tradiciones, costumbres o por el modelo económico globalizado. Dicho modelo económico, viene incidiendo de tal manera que pone en riesgo no solo la salud humana, sino los ecosistemas naturales.

El comercio ilegal en condiciones antihigiénicas de especies silvestres, han acelerando la transmisión de patógenos como bacterias o virus, que afectan principalmente al hombre. Situación que en eñ año 2019, se le atribuyó al surgimiento del Covid-19 en el mercado de Wuhan, en la provincia china de Hubei, (WWF INTERNACIONAL, 2020). Esta desafortunada experiencia que el mundo vive por causa de las inadecuadas interacciones entre los humunos y la fauna, es una manera de reflexionar y cuestionar la forma de intervenir la biodiversidad. 
Ahora bien, la biodiversidad en tiempos de pandemia, también puede ser vista desde el ámbito paisajístico o estético. Pues, no se puede desconocer, que la pandemia ha brindado espacios de resurgimiento de especies en fauna y flora a lo largo y ancho del planeta. Ante este nuevo contexto, algunos paises como Italia, hoy ofrece visitas virtuales a partir de aplicaciones para teléfonos inteligentes creadas por el departamento de Patrimonio Cultural, como por ejemplo la visita al patrimonio submarino de la "Sicilia Archeologica".

La directora de la UNESCO, Audrey Azoulay (2020), invita a la reflexión en el mundo asegurando que "Quizás la pandemia actual sea una oportunidad para tomar nota del enorme costo colectivo de los cambios radicales en los estilos de vida... y fomentar una mejor gestión de estos cambios, particularmente en nuestra relación con la naturaleza" (p. 3).

Ante la crisis mundial generada por la pandemia del Covid-19, la UNESCO tuvo que postergar para el año 2021 los diversos encuentros internacionales programados para 2020, entre estos, el Congreso Mundial de la Conservación, en Marsella (Francia), la Conferencia Oceánica de las Naciones Unidas, en Lisboa (Portugal).

Con el fin de responder a los desafíos que el Covid-19 ha impuesto a la humanidad, las estrategias regionales han cogido mayor fuerza y protagonismo. Los países insulares del Pacífico que aún no han sido afectados por la pandemia como medio de defensa han tenido que restringir el turismo, incidiendo de manera negativa en el desarrollo económico de las islas y en las altas tasas de desempleo.

La comunidad del Caribe, realizó el "Primer Diálogo Regional sobre Cultura en un Ambiente COVID-19" celebrado en el mes de mayo de 2020. El doctor Douglas Slater, Secretario General Adjunto de Desarrollo Humano y Social de CARICOM, expresó la importancia de la cultura y la creatividad para enfrentar los desafíos que el Covid-19 plantea al mundo. En este sentido, se plantearon alternativas en plataformas digitales para la realización de eventos.

Con el fin de mitigar el impacto económico en las instituciones dedicadas al desarrollo cultural, la Comisión Europea adoptó ayudas estatales, apoyo financiero, reembolso de servicios no realizados e implementación de tecnologías digitales, entre otros. 
En América Latina, los efectos del Covid-19 han sido considerados muy negativos para el sector cultural, razón por la cual se ha instado a las organizaciones internacionales, nacionales y regionales para apoyar dicho sector.

La UNESCO durante el año 2020 adelantó iniciativas para mitigar el impacto de la pandemia en la industria de la cultura, como por ejemplo: \#-shareOurHeritage, campaña lanzada para compartir videos y visitas virtuales, reunión en línea de ministros de Cultura, lanzamiento de la plataforma del Patrimonio Cultural Inmaterial, Soluciones Urbanas, aprendiendo de las respuestas de las ciudades al COVID-19, entre otros (Organización de las Naciones Unidas para la Educación, la Ciencia y la Cultura - UNESCO, 2020).

La pandemia puso de manifiesto la vulnerabilidad de la industria en el sector cultural para continuar en la conservación de los patrimonios de la humanidad, a partir de la contratación de talento humano experto, asignación de recursos y visitas turísticas que ayudan a mantener la riqueza natural y los monumentos construidos por el hombre. El peso económico del sector cultural, tanto para su subsistencia y consolidación de recursos por vía del turismo, han develado la fragilidad en este campo en todo el territorio.

Así mismo, la biodiversidad como escenario natural para la vida y la subsistencia de la flora y la fauna, ha sido afectada principalmente por el cambio climático originado por las acciones antrópicas. Los efectos de dichas acciones en los ecosistemas son notorios, como el blanqueamiento de los corales en Australia, la disminución de las especies animales y vegetales y los incendios desmedidos en las Montañas Azules, entre otros, que son muestra de cómo el humano depreda el sistema natural. (Organización de las Naciones Unidas para la Educación, la Ciencia y la Cultura-UNESCO, 2020).

De acuerdo con la publicación sobre la conservación de los tesoros naturales del mundo, en 2020 se esperaba que fuera el año que consolidaría las decisiones, políticas y estrategias sobre la biodiversidad en el mundo. Colombia, con su riqueza natural, aporta de manera significativa a la conservación de los ecosistemas, la biodiversidad y las áreas protegidas. 
Las áreas protegidas, además de ofrecer salud física y bienestar emocional, son un escenario para llevar a cabo estrategias en educación ambiental, investigación científica, recreación y turismo. De igual manera, se establecen sinergias entre la biodiversidad natural en flora y fauna y la diversidad cultural, vistas desde los grupos étnicos presentes en la región.

Es importante destacar cómo en Colombia se cuenta con 1.244 de áreas protegidas, con una extensión 31'287.122 hectáreas, y que algunos lugares cuentan con resguardos indígenas, que en alianza con la autoridad ambiental, trabajan para afianzar procesos de interculturalidad, diversidad y conservación de la biodiversidad. (Organización de las Naciones Unidas para la Educación, la Ciencia y la Cultura-UNESCO, 2020).

Sin embargo, en el contexto de la pandemia las medidas de aislamiento, confinamiento, y restricción turística han permitido que las fuentes hídricas recobraran sus colores cristalinos, que los animales puedan deambular de una manera más libre por el planeta. Como ejemplo, varias especies de animales llegaron al paisaje urbano, tras la cuarentena en los diferentes países: los patos que recorrieron París, en Francia; un puma por las calles de Santiago en Chile, etc.

\section{La biodiversidad dependiente de la industria}

La dependencia económica de ingresos derivados del turismo para realizar trabajos de conservación en los 213 sitios naturales y 50 sitios marinos considerados Patrimonio Mundial por organizaciones como la UNESCO, ponen en peligro su estabilidad. En abril de 2020, el Consejo Mundial de Viajes y Turismo, reportó que podría perderse el 2,1 billones de dólares del PIB por la escases de visitas de turistas, lo cual genera un panorama incierto e inestable en los sitios naturales como los arrecifes de coral fundamentales en lucha contra el cambio climático.

Finalizando el año 2020, se establecieron estrategias para activar la economía del turismo y, por ende, el empleo. La reducción de impuestos, el valor de tiquetes y hoteles incentivaron a los individuos para visitar principalmente los lugares agroturísticos.

La naturaleza, entre otros aspectos, le brinda al hombre diversos escenarios para su supervivenvia. En este sentido, los paisajes, la riqueza 
hídrica, el avistamiento de flora y fauna se han constituido en un interés socioeconómico del cual se lucran los individuos y las instituciones. Sin embargo, en Colombia todavía falta mucho por hacer en el campo educativo para el turista, que disfruta de la riqueza natural, y para el empresario que busca beneficio económico.

Se hace necesaria la adopción de estrategias pedagógicas que incentiven una sinergia entre los sistemas natural y sociocultural para el disfrute responsable de la naturaleza. La pandemia ha puesto en escena la necesidad de reconsiderar las prácticas cotidianas que el hombre, como parte de la naturaleza, ha venido ejerciendo de manera insensible e irresponsable. Es un problema con ojos de oportunidad para la vida en el planeta.

\section{La comercialización de la biodiversidad silvestre}

La comercialización, el tráfico y el consumo de la biodiversidad silvestre afectan la conservación de las especies, acarreando problemas de índole natural y sanitaria. Natural, porque atenta contra la supervivencia y la conservación de las especies; sanitario, porque puede generar la transmisión de enfermedades zoonóticas, que atentan contra la población humana en el planeta.

Mientras exista quién compre y quién venda, la comercialización de biodiversidad en fauna silvestre persistirá de manera clandestina. Se hace necesario diseñar e implementar procesos educativos que brinden conocimiento, acciones de prevención y de atención a las problemáticas suscitadas por la comercialización de biodiversidad silvestre. De igual forma, el acompañamiento de las autoridades ambientales para la prevención, y aplicación de los mecanismos de control y sanción eficientes a quienes infrinjan la norma de manera reiterativa.

\section{Una mirada cultural étnica}

Una de las comunidades menos atendidas por los diferentes gobiernos, es la de los indígenas. Según National Geographic, aproximadamente la protección del $80 \%$ de la diversidad en el planeta ha estado en manos de los pueblos indígenas, y son guardianes de casi el $20 \%$ del territorio. En este sentido, se congujan dos aspectos de importancia y en riesgo para la 
humanidad. El primer aspecto es la cultura, representada en este caso por los pueblos indígenas, y el otro aspecto, la biodiversidad natural. Ante la pandeminia del Covid-19, la ONU se ha pronunciado frente a la necesidad de los derechos de los indígenas en torno a la salud (Organización de las Naciones Unidas para la Educación, la Ciencia y la Cultura - UNESCO, 2020).

América Latina y el Caribe, gozan de una diversidad natural y cultural de importancia. No obstante, el Covid-19 ha hecho evidente la ausencia de un sistema de salud equitativo, que atienda las necesidades específicas de los indígenas, afrodescendientes y demás grupos étnicos. En el año 2017, se reconocen las diferencias entre los grupos étnicos, promoviendo un enfoque intercultural para avanzar en temas de salud, razón por la cual consolidó la política sobre etnicidad y salud (Organización Panamericana de la Salud, 2020).

De otro lado, la producción de alimento al interior de las comunidades campesinas y étnicas en estos tiempos de pandemia, ha puesto sobre la mesa la importancia de los mercados locales. La encuesta realizada por la UNESCO sobre el impacto de la pandemia en el patrimonio cultural inmaterial, evidenció que las recetas tradicionales y la comida local han motivado el interés por la agricultura, uso de plantas silvestres y crianza de animales de manera tradicional y orgánica. Para el caso colombiano, en la comunidad indígena Misak los ancianos comparten las técnicas de producción agrícola tradicional con los jóvenes de su población (Organización de las Naciones Unidas para la Educación, la Ciencia y la Cultura - UNESCO, 2020)

Los pueblos indígenas son de suma importancia como patrimionio cultural inmaterial, así como desde los saberes y prácticas ancestrales alrededor de la conservación de la biodiversidad, como quiera que poseen experiencia para mitigar, adaptar y reducir los impactos climáticos en el territorio. Según, Bruna Rocha profesoara de arqueologia de la Universidad Federal para Occidente en Brasil, los ancianos de los pueblos indígenas tiene un fuerte conocimiento del medio ambiente, el territorio, historia, medicamentos naturales, orientación espiritual y política, elementos fundamentales para el reconocimiento en el territorio. 
Para José Francisco Cali Tizay, Relator Especial para los derechos de los pueblos indígenas de las Naciones Unidas, la pandemia, entre otros aspectos, deja como enseñanza valorar lo colectivo sobre lo individual y construir un mundo inclusivo en los diferentes contextos culturales.

Es importante mencionar que se requiere implementar estrategias que conlleven a una sociedad mejor estructurada, tolerante, resistente e insistente ante un mundo globalizado y hegemónico. En este sentido, el brote del Covid-19 abre la puerta a la oportunidad de reconstruir un mundo con una mirada intercultural, integral e inclusiva a partir de procesos pedagógicos contextualizados, construido con los sujetos sociales en el territorio.

\section{OPORTUNIDADES EN TIEMPOS DE INCERTIDUMBRE}

\section{Construcción de una cultura ambiental}

La situación de crisis sanitaria por la que el mundo está atravesando es lamentable; sin embargo, se requiere que la humanidad reflexione e inicie cambios culturales a favor de la vida en donde el Estado, las instituciones y los individuos adopten iniciativas que puedan atender en primer lugar la subsistencia de los seres vivos, así como la activación paulatina de la economía a partir de medidas y prácticas culturales amigables con el entorno.

Se hace necesario, generar caminos distintos al sistema colonial y neoliberal que por largos años ha perdurado en el territorio, donde se privilegia el dominio y las riquezas de unos pocos sacrificando la naturaleza y los sujetos sociales vulnerables ante el sistema económico. Esta construcción, debe cimentarse en estructuras de pensamiento y acción expresadas en comportamientos inclusivos, innovadores, sensibles y conocedores de la naturaleza. Se requiere avanzar hacia la construcción de una cultura ambiental emergente, que incida de manera positiva en la naturaleza, garantizando la vida y permanencia de los seres vivos y no vivos en el sistema natural.

La crisis sanitaria y ambiental generada por la pandemia requiere mayores esfuerzos para atender poblaciones vulnerables, donde prima la pobreza, altos índices de contaminación, y poca o nula presencia del 
Estado. No obstante, la construcción de una cultura ambiental en estos contextos, requiere la articulación entre los actores de cada región y las instituciones públicas y privadas para que colaboren a favor del ambiente.

Giménez - Candela (2020) considera que se requiere replantear la ética alrededor de la salud y la relación del hombre con la naturaleza, así como la responsabilidad social en un mundo globalizado, las acciones concretas para la preservación de la biodiversidad natural y cultural de las regiones.

La crisis sanitaria y la crisis económica que la pandemia ha traído consigo, instan a los gobiernos para que replanteen el camino a seguir, tomen las medidas para contener la propagación de la pandemia y viabilicen la economía de cada país. Sin embargo, mitigar el impacto en estos dos ejes requiere reconsiderar la restricciones aplicadas en la movilidad de los individuos, variable que incide en el contagio del Covid-19, y las nuevas mutaciones registradas recientemente. Se hace necesario evaluar las políticas adecuadas para flexibilizar las restricciones o cuarentenas (Azerrat, Ratto, \& Fantozzi, 2021).

La cultura está sujeta no solo al comportamiento, las tradiciones o las costumbres apropiadas o inapropiadas de los individuos; también está sujeta a los intereses económicos a costa de la sobreexplotación de los recursos naturales y su biodiversidad.

Hoy, el Covid-19, entre otros aspectos, ha puesto en evidencia la oportunidad de revisar las prácticas cotidianas que el hombre, como parte del sistema natural, requiere reconsiderar para la convivencia con las especies animales y vegetales. Uno de los desafíos que se consideran en este documento es lograr estructurar estrategias alternativas que puedan sensibilizar y formar al ciudadano para que asuma una postura responsable con su accionar en el contexto.

\section{Revisión y ajustes al modelo económico}

Atender el impacto de las diversas actividades antrópicas en la naturaleza como por ejemplo, el establecimiento de cultivos a gran escala, la cual propicia agotamiento del suelo por el uso indiscriminado de agroquímicos, contaminación de fuentes hídricas por vertimientos y escorrentía; la explotación ganadera que ocasiona compactación del suelo; 
zonas de minería a cielo abierto, que deteriora el suelo, la biodiversidad, genera desplazamiento social, y la contaminación del agua por el uso de químicos para extracción de minerales etc. Las consecuencias de dichas actividades, requieren ajustes en las políticas públicas ambientales, de producción y consumo, las cuales preferencialmente se limitan a la consolidación de datos, mediciones, inventarios, etc. Esta información recolectada no cobra importancia si no se interpela la inadecuada forma de intervenir el sistema natural. En este sentido, se requiere que la dimensión ambiental sea considerada de manera transversal en las políticas públicas sobre el uso y la ocupación del suelo, la vivienda, la movilidad, la infraestructura, la participación ciudadana, entre otras (Duquino Rojas, 2018).

Hoy, en su gran mayoría la humanidad está sintiendo las consecuencias de un estilo de vida extractivista, depredador de la biodiversidad, antropocentrista, donde se ha venido privilegiando un modelo económico neoliberal arrasador de los recursos naturales e indolente con el planeta, que privilegia el capital privado a costa de la naturaleza. La pandemia ha subordinado al hombre que, hoy en pleno siglo XXI, con mayor capacidad tecnológica y científica, tiene en crisis la salud humana, y la economía para su subsistencia, tal como lo anunciaba Enrique Leff:

\footnotetext{
"Nos ha tocado vivir una etapa histórica marcada por la crisis ambiental; y esta crisis ambiental no es una crisis cíclica más del capital, ni la de una recesión económica, aunque también conlleve a ella en estos momentos, cuando la crisis energética se conjuga con una crisis alimentaria. La crisis ambiental es una crisis civilizatoria, y en un sentido muy fuerte, es decir, que hemos llegado al punto de haber puesto en peligro no solamente la biodiversidad del planeta, sino la vida humana, y junto con ello algo sustantivo de la vida humana, el sentido de la vida“ (Leff, 2008).
}

El Secretario General de la ONU Antonio Gutiérrez, recalca la urgencia de reconstruir la relación con los demás actores de la naturaleza. Las prácticas extractivas, la agricultura intensiva, la deforestación, el modelo económico donde prima la aceleración en todos los procesos de producción y consumo, han conducido a que el planeta se enfrente a un virus que coge fuerza, que se transforma y pone en peligro la vida de uno de los integrantes del sistema natural. El mundo empieza a experimentar fuertes cambios en la salud y la economía principalmente (Miyahira, 2020). 
El World Economic Forum (WEF) señala que la pandemia es una de las pruebas más difíciles de superar en el mundo moderno. No solo atenta contra la vida misma, sino que además se lleva por delante la economía, la salud y las dinámicas sociales propias de un mundo administrado desde el extractivismo y el agotamiento de los recursos naturales. Además, identificó tres temáticas en las que se puede agrupar el impacto de la pandemia, así:

1. Las acciones de respuesta gubernamental, encaminadas al apoyo económico y financiero por el confinamiento, y medidas de distanciamiento social.

2. Repercusión sobre la economía: acciones como el ERTE (expedientes de regulación temporal de empleo) resulta ser una estrategia para mitigar la afectación en el mercado laboral, financiero, el comercio, el turismo, etc.

3. Repercusión en el sistema sanitario: medidas esenciales para la recuperación de las personas afectadas, investigación orientada a la vacuna contra el Covid-19, y acceso a materiales de uso médico, entre otros (López \& Durán, 2020).

Así mismo, los informes del Fondo Mundial para la Naturaleza WWF International, manifiestan que, a los riesgos ambientales como los desastres naturales, las afectaciones ambientales por acciones antrópicas, la crisis alimentaria, el cambio climático, la perdida de la biodiversidad, se le adicionan los efectos generados por la pandemia del Covid-19. Hoy, la incidencia de las actividades socioeconómicas mal orientadas y aplicadas en el contexto global, muestran la fragilidad de la vida, arrinconada en una crisis sanitaria y económica.

Actualmente, los principales temas en los que los gobiernos están concentrando sus esfuerzos, se relacionan con la salud humana, la salud económica, así como la salud ambiental como primera línea, para atender las dos primeras. A partir del año 2020, la pandemia ha planteado desafíos para los líderes del mundo, la comunidad científica y la ciudadanía, a fin de buscar estrategias que ayuden a prevenir y resolver las diversas problemáticas de índole educativa, social, política, económica y ambiental. 


\section{LA BIODIVERSIDAD COMO ESTRATEGIA PEDAGÓGICA ALTERNATIVA COMUNITARIA-EPAC}

La consolidación de este documento busca proponer una estrategia pedagógica alternativa comunitaria, con el objetivo de iniciar un camino real y participativo de los diferentes interlocutores de la sociedad, en la reformulación de una cultura ambiental responsable con el entorno y su biodiversidad.

González (2008) manifiesta la necesidad local y global de revisar y ajustar la relación individual y colectiva con el medio ambiente. No se puede seguir viendo las problemáticas de manera aislada, es así como la pandemia ha puesto de manera clara y evidente la relación entre el sistema natural y el sistema sociocultural.

¿Por qué la investigación en biodiversidad puede convertirse en el contexto y en el medio formativo para promover cambios responsables en la cultural ambiental?

La Agenda 21 definió la biodiversidad como la variedad de especies en flora y fauna, ecosistemas y genes existentes en el planeta. Colombia le ha apostado a la conservación de la riqueza natural desde hace más de 50 años; las áreas protegidas se consideran como un escenario de especial atención para mantener la riqueza en flora, fauna, étnica y las sinergias que se suscitan entre los sistemas natural y social, presentes en el territorio. Es así como se cuenta con una extensión de 31'287.122 hectáreas distribuidas en 1.244 áreas protegidas (Organización de las Naciones Unidas para la Educación, la Ciencia y la Cultura-UNESCO, 2020).

Si bien, desde Parques Nacionales Naturales de Colombia se ha venido trabajando con las comunidades para la conservación de la biodiversidad natural y cultural, todavía hay camino por recorrer en este campo. El contexto de la pandemia reitera la oportunidad para construir alternativas pedagógicas alrededor de la biodiversidad y la cultura, como dos ejes articuladores importantes para la existencia y sobrevivencia de las especies en la naturaleza.

Es por ello que se plantea una estrategia pedagógica alternativa comunitaria, que en una primera fase pretenderá llegar tanto al contexto 
urbano como al rural, abordando procesos investigativos y formativos a partir de tres ejes, así:

1. La biodiversidad como ambiente de aprendizaje

2. La biodiversidad como ambiente de investigación

3. La biodiversidad como sistema alternativo ecosocial

El primero, la biodiversidad como ambiente de aprendizaje, busca que el ciudadano comprenda los elementos conceptuales, actitudinales y praxiológicos, a partir de procesos formativos con enfoque ecológico, para que en un primer momento reconozca y valore el entorno, reflexione sobre el impacto de las actividades diarias en el ecosistema, y finalmente apropie y articule saberes alrededor del manejo, uso y conservación de la biodiversidad.

Es importante destacar el valor fundamental de los presaberes de las comunidades, con el fin de ajustar y consolidar aprendizajes contextualizados, teniendo en cuenta los elementos potenciales y diferenciales de cada poblacion.

La biodiversidad como ambiente de investigación le permitirá al individuo y a la comunidad partir de las preguntas cotidianas o problemas de investigación in situ, leer el entorno, identificar, atender y prevenir situaciones que pongan en riesgo los ecosistemas y su riqueza en flora y fauna.

Concebir la investigación como una oportunidad para profundizar en los temas de interés socioambiental puede propiciar espacios participativos e interdisciplinarios en la construcción de conocimiento social y científico, que permita ajustar y fortalecer la cultura ambiental en la región.

Finalmente, la biodiversidad como sistema alternativo ecosocial se propone, entre otros aspectos, consolidar de manera conjunta un sistema que integre los ecosistemas y las comunidades, brindando elementos diferenciales según sea el contexto y las dinámicas de los individuos.

Este enfoque busca consolidar redes de conocimiento contextualizado, donde se recojan las características, especificidades y prácticas cotidianas de los individuos con la flora, la fauna, el paisaje, las fuentes hídricas, 
a fin de consolidar alternativas de solución para atender y prevenir las problemáticas socioambientales presentes enel territorio.

Estos tres ejes podrán dar cuenta de las interacciones que se llevan a cabo entre los diferentes ecosistemas y el contexto, con e fin de comprender, leer, investigar y producir conocimiento que conlleve a la adopción de una cultura ambiental responsable con el planeta.

Esta sinergia entre la biodiversidad y la adopción de una cultura ambiental se establece como una alternativa que pueda responder a los retos que hoy el mundo demanda.

\section{Conclusiones}

La biodiversidad y la cultura han estado articuladas de manera distinta a lo largo de la historia. Sin embargo, el contexto de una pandemia inesperada ha puesto en escena las presiones aceleradas al sistema natural y, por ende, sus consecuencias.

Ahora bien, la forma inadecuada de intervenir los ecosistemas por parte del hombre ha surtido un efecto en aspectos relevantes como son la salud, la economía, el ambiente, la educación y la sociedad en general, de tal manera que los gobiernos se han visto en la imperiosa necesidad de dar un vuelco a las estrategias y modos de intervenir el territorio, con el fin de atender las necesidades por las que hoy el mundo atraviesa.

En este sentido, desde los diferentes ámbitos sociales y académicos se hace necesario proponer alternativas que permitan ver en la pandemia oportunidades de reconversión social, económica, política, y educativa, entre otras.

El tema de biodiversidad y cultura considerado en este documento, busca ver una oportunidad pedagógica en medio de una problemática global, donde se privilegien las sinergias entre dichos ejes temáticos (biodiversidad y cultura). Para ello, se propone la biodiversidad como estrategia pedagógica alternativa comunitaria-EPAC, con el fin de avanzar hacia los ajustes necesarios que hoy requiere de manera urgente el sistema socioambiental. 
Promover la adopción de una cultura ambiental y una educación ecológica de manera individual y colectiva permitirá mitigar la incidencia de las presiones antrópicas a la biodiversidad en los diferentes ecosistemas presentes en el territorio.

La cultura y la biodiversidad reflejan una fuerte articulación en la subsistencia del hombre, razón por la cual se hace necesario consolidar estrategias alternativas que propicien una mejor gestión, manejo, uso de la naturaleza, así como promover cambios en los estilos de vida.

\section{Referencias bibliográficas}

Azerrat, J., Ratto, M., \& Fantozzi, A. (2021). ¿Gobernar es cuidar?. Trabajo y Sociedad, No. 36.

Duquino Rojas, L. G. (2018). Sustentabilidad ambiental urbana, alternativas para una política pública ambiental. Bitácora Urbano Territorial, 141-149.

García Echeverry, F. A., Moreno Amézquita, J. E., Pinto Bustamante, B. J., \& Gómez Cordoba, A. (2020). El derecho a la salud en tiempos de pandemia en

Colombia: entre la inequidad endémica y el estado de emergencia. Revista Colombiana de Bioética. Vol. 15.

Giménez - Candela, M. (2020). El colapso del pasado: COVID-19. de Derecho Animal, Vol. 11/2.

González, E. (2008). Educación, Medio Ambiente y Sustentabilidad.

Idrovo, A.-J., Manrique, E.-F., \& Nieves, G.-M. (2020). Crónica de una pandemia anunciada: caso Santander (Parte 1). Salud UIS.

Leff, E. (2008). Discursos sustentables. México: Siglo XXI.

López, A., \& Durán, G. (2020). Covid-19 y medio ambiente: alcance y escenarios futuros. Economistas Colegio de Madrid. No. 170, 82.

Miyahira, J. (2020). Lo que nos puede traer la pandemia. Revista Médica Herediana, Vol. 31, No. 2.

Organización de las Naciones Unidas para la Educación, la Ciencia y la Cultura UNESCO. (2020). Boletín Semanal No. 8.

Organización de las Naciones Unidas para la Educación, la Ciencia y la Cultura UNESCO. (2020). Cultura \& Covid-19, Impacto \& Respuesta.

Organización de las Naciones Unidas para la Educación, la Ciencia y la CulturaUNESCO. (2020). Patrimonio Mundial, No. 96.

Organización Panamericana de la Salud (2020). Consideraciones relativas a los pueblos indigenas, afrodescendientes y otros grupos étnicos durante la pandemia COVID-19.

WWF INTERNACIONAL. (2020). Pérdida de la naturaleza y el surgimiento de pandemias. Protegiendo la salud humana y planetaria. 